\title{
The Effects of a Subsidy for Grassland Protection on Livestock Numbers, Grazing Intensity, and Herders' Income in Inner Mongolia
}

\author{
Liping Gao , Henry W. Kinnucan ${ }^{\mathrm{b},}{ }^{*}$; Yaoqi Zhangc; Guanghua Qiaod
}

\begin{abstract}
Primary data from 262 pastoral households in Inner Mongolia are analyzed to determine the effects of a subsidy for grassland protection on livestock numbers, grazing intensity, and herders' income. Econometric models are estimated to determine the effects of the subsidy on each component of the intensity ratio (sheep-equivalent livestock units and grassland). Results suggest the subsidy increased the quantity of grassland controlled by the household. However, the effects on livestock units are mixed, with two of the four studied prefectures (Ordos and Ulanqab) showing a positive response, and two (Hulunbuir and Xilingol) showing a negative response. Inserting the parameter estimates from the livestock, grassland, and income functions into a structural model of grazing intensity, results suggest each $1 \%$ increase in subsidy reduces grazing intensity by between $0.168 \%$ and $0.532 \%$ depending on the prefecture, and increases herders' income by between $0.144 \%$ and $0.670 \%$. By way of comparison, each additional year of education increases herders' income by $8.7 \%$ and reduces grazing intensity by $3.6 \%$. Thus, education is not to be overlooked as a policy tool for achieving conservation goals.
\end{abstract}

Keywords: Grassland policy; Grazing intensity; Government subsidy; Inner Mongolia JEL: Q11; Q18; Q54; Q58

\footnotetext{
a Department of Finance and Economics, Georgia Southern University, GA 30458, USA. Tel: 1-912-478-0184. Email: sophiagao1031@gmail.com.

b, ${ }^{*}$ Corresponding author. Department of Agricultural Economics and Rural Sociology, Auburn University, AL 36849, USA. Tel: 1344-844-5614. Email kinnuhw@auburn.edu.

c School of Forestry \& Wildlife Sciences, Auburn University, AL 36849, USA. Tel: 1-344-844-1041. Email: zhangy3@auburn.edu.

${ }^{d}$ College of Economics and Management, Inner Mongolia Agricultural University, Huhhot, 010019, P.R. China
} 


\section{Introduction}

In semi-natural and managed rangelands, livestock grazing is a widespread and dominant land-use activity (Fleischner, 1996; Zhao et al., 2005; Han et al., 2008: Harris, 2010). Continuous heavy grazing causes soil surface disturbance, vegetation cover reduction, and rangeland degradation (Johnston et al., 1971; Brown and Mcdonald, 1995; Curtin, 2002; Pakeman et al., 2003; Kemp et al., 2012, Yang et al., 2012, Hao et al., 2014). Grazing control is a necessary component of grassland management (Hulme et al., 1999; Schönbach et al., 2011). It can be used to harmonize potentially conflicting land use objectives, or to emphasize a particular objective within a given management regime (Grant et al., 1996). The benefits of grazing control and reduced grazing intensity are supported by a large body of research on grassland restoration (e.g., Owen, 1977; Gibson et al., 1992; Smith et al., 1996; Leriche et al., 2001; Tallowin et al., 2005; Marriot et al., 2009). Reducing livestock numbers or increasing the efficiency of livestock production has the potential to reduce methane emissions and increase the ability of grasslands to sequester carbon (Kemp et al., 2012).

A growing body of research suggests rangeland degradation is a long term and large scale environmental problem in China, especially in the Northern and Northwestern provinces of Xinjiang, Qinghai, Gansu, Ningxia, and Inner Mongolia (Banks, 2001; Meyer, 2006; Ho and Azadi, 2010; Wang et al, 2013; Kolås, 2014). Identifying strategies that restore the ecosystem functions of grassland while at the same time 
improving the livelihoods of traditional pastoralists pose a major challenge for policy makers (Han et al., 2008; Brown et al., 2011; Kemp et al., 2012; Waldron et al., 2011; David et al, 2013; Li et al., 2014).

To protect and restore ecosystems China has implemented several conservation programs. The "Grain-for-Green" program initiated in 1999 and widely implemented in 2003 is perhaps the most notable program. Its primary aim was to convert marginal farmland to forest and grassland (State Council of China, 2002; Feng et al., 2005). In terms of Inner Mongolia, the Beijing-Tianjin sandstorm source control project initiated in 2001 is notable. Its aim was to build a greenbelt north of Beijing (Jiang, 2006; Yeh, 2009; Wang et al., 2013). Even more significant, however, is the "Grazing Control and Grassland Protection Subsidy Program" initiated in 2011 (State Council of China, 2011; Hua and Squires, 2014; Zhen et al., 2014; Hu et al., 2015). This program uses subsidies as an incentive to control livestock numbers and reduce grazing intensity. China's central government is projected to spend $\$ 2.14$ billion on the program over five years, of which $\$ 0.65$ billion is allocated for Inner Mongolia starting in $2011 .{ }^{1}$

\footnotetext{
${ }^{1}$ Payments under the program are to be provided for i) grassland where grazing is no longer permitted; ii) maintaining a favorable forage-livestock balance; iii) selected animal husbandry practices such as growing superior seed; and iv) production material (such as purchases of new equipment). To be eligible for the subsidies the household is required to reduce livestock to a preset level depending on herd size. In areas where livestock are numerous, households are given five years to comply with the specified reduction; in other areas compliance must be accomplished within three years. There are certain restrictions on the subsidies. For example, in the case of animal husbandry practices, if the household keeps grassland in the same situation as before 2010, first- and second-year subsidies are limited to $\$ 23.88 / \mathrm{ha}$. Subsidies for one-year practices like growing superior seed are $\$ 35.82 / \mathrm{ha}$, and for new forage shrubs is \$23.88/ha (DAIM, 2011).
} 
The purpose of this research is to determine the effects of the subsidy program on livestock numbers, grazing intensity, and herders' income. A secondary purpose is to determine the extent to which the vicious-cycle hypothesis set forth by Li et al. (2014) applies to Inner Mongolia. This hypothesis asserts that herders respond to decreased productivity of their grasslands associated with overgrazing by increasing livestock numbers in a bid to maintain living standards. The resulting increase in stocking rates degrades further the grassland, and the cycle repeats itself (see Figure 1). The viciouscycle hypothesis implies that grassland in the first instance is overgrazed. ${ }^{2}$ If this is true, an increase in grazing intensity should reduce herders' income at the margin. We test this hypothesis by estimating a structural model of herders' behavior that includes income as one of the equations.

Previous research has been useful in documenting the environmental consequences of rangeland degradation in China (e.g., Banks, 2001; Meyer, 2006; Ho and Azadi, 2010; Kemp et al., 2012; Wang et al., 2013), and in indicating the potential benefits of grazing control and reduced grazing intensity on grasslands and the ecosystem (e.g.,

\footnotetext{
${ }^{2}$ In his review of the literature, Harris (2010) identifies seven "putative drivers" of rangeland degradation in northern China: an inherently harsh climate and fragile soils, global climate change, damage by "rodents," unsustainable conversion of rangelands to cultivated crops, "backward" pastoral production systems, privatization and/or sedentarization (including fencing), and overstocking. In assessing the evidence adduced for each driver, Harris concludes that cause and effect has not been established for any of them, including overstocking. A basic reason is that studies often fail to cast their analyses in the form of hypotheses to be tested, or do so in such a vague manner as to preclude valid inferences about causal mechanisms. Until the science improves, Harris argues that even assertions about the extent of grassland degradation in China (commonly cited to be some $90 \%$ of all grasslands) must be treated with caution. This caution motivates our testing the vicious-cycle hypothesis, as it is possible that overstocking per se is not an issue in Inner Mongolia.
} 
Owen, 1977; Gibson et al., 1992; Smith et al., 1996; Leriche et al., 2001; Tallowin et al., 2005;

Marriott et al., 2009; Kemp and Michalk, 2011). Studies specific to Inner Mongolia document the effects of sandstorm control and other government policies on inter alia grassland restoration (Jiang, 2006; Yeh, 2009; Wang et al., 2013). This study fills a gap in the literature by quantifying the effects of the subsidy program on herders' behavior as it relates to four key variables; namely, livestock numbers, grassland holdings, grazing intensity, and income.

The paper is organized as follows. Section 2 presents the theoretical framework for the analysis. Sections 3 and 4 describe the data, empirical model, and regression results. Section 5 presents and interprets the reduced-form elasticities estimated from the model. Section 6 concludes.

\section{Theoretical Framework}

\subsection{Structural model}

Imagine a household that grazes $Q$ units of livestock on GL units of grassland. To encourage conservation, the government provides the household that follows specified conservation practices a subsidy equal to $S$. Grassland controlled by the household is a function of the subsidy, but also the household's income level $Y$. The subsidy influences $Q$ indirectly through its effect on $G L$, but also directly through its effect on the expected profitability of the livestock enterprise. The income received by the household is a function of livestock numbers and grazing intensity. 
With these assumptions, the equations describing the household's response to the subsidy may be written as follows:

$$
\begin{array}{ll}
Q=f(G L, \bar{S}) & (\partial Q / \partial G L>0, \partial Q / \partial S<0) \\
G L=g(Y, \bar{S}) & (\partial G L / \partial Y>0, \partial G L / \partial S>0) \\
Y=g(Q, I) & (\partial Y / \partial Q>0, \partial Y / \partial I>0)
\end{array}
$$

where the overbar $\left(^{-}\right)$denotes an exogenous variable. Livestock units are an increasing function of grassland, and the grassland controlled by the household is an increasing function of income. The subsidy provides incentives to increase land holdings, but also imposes compliance costs. Thus, livestock units are a decreasing function of subsidy, and grassland is an increasing function of subsidy. Income is an increasing function of livestock units and grazing intensity. The structural model is completed with an identity that defines grazing intensity

$$
I=Q / G L .
$$

The model consists of four endogenous variables $(Q, G L, Y, I)$ and one exogenous variable $(\bar{S})$. Other exogenous variables that affect the equilibrium levels of livestock, grassland, and income are suppressed. Of key interest is the effect of an increase in the subsidy on grazing intensity and herders' income given the posited relationships.

To determine that, first write the model in proportionate change form

$$
\begin{array}{ll}
Q^{*}=\alpha_{G L} G L^{*}+\alpha_{S} \bar{S}^{*} & \left(\alpha_{G L}>0, \alpha_{S}<0\right) \\
G L^{*}=\beta_{Y} Y^{*}+\beta_{S} \bar{S}^{*} & \left(\beta_{Y}>0, \beta_{S}>0\right) \\
Y^{*}=\gamma_{Q} Q^{*}+\gamma_{I} I^{*} & \left(\gamma_{Q}>0, \gamma_{I}>0\right)
\end{array}
$$




$$
I^{*}=Q^{*}-G L^{*}
$$

The asterisk $\left(^{*}\right)$ indicates proportionate change (e.g., $Q^{*}=d Q / Q$ ) and the Greek symbols are structural elasticities. Specifically, $\alpha_{G L}$ and $\alpha_{S}$ tell the percentage effects on livestock units of isolated one percent increases in grassland and subsidy, respectively; $\beta_{Y}$ and $\beta_{S}$ tell the percentage effects on grassland of isolated one percent increases in income and subsidy, respectively; and $\gamma_{Q}$ and $\gamma_{I}$ tell the percentage effects on income of isolated one percent increases in livestock units and grazing intensity, respectively.

\subsection{Reduced form when income is exogenous}

What hypotheses can be deduced from the model? The answer is found by solving the model for the reduced form. For this purpose, we drop equation (7) from the model to treat income as temporarily exogenous and solve the remaining equations simultaneously for intensity in terms of the exogenous variables to yield

$$
I^{*}=-\beta_{Y}\left(1-\alpha_{G L}\right) \bar{Y}^{*}+\left(\alpha_{S}-\beta_{S}\left(1-\alpha_{G L}\right)\right) \bar{S}^{*} .
$$

With the maintained hypothesis that livestock units are a decreasing function of subsidy $\left(\alpha_{S}<0\right)$ and grassland is an increasing function of income and subsidy $\left(\beta_{Y}>0\right.$ and $\beta_{S}>$ $0)$, the ability of the subsidy to reduce intensity when income is exogenous hinges on the responsiveness of livestock units to changes in grassland, i.e., on the size of $\alpha_{G L}$. In particular, if $\alpha_{G L}=1$ equation (9) reduces to $I^{*}=\alpha_{S} \bar{S}^{*}$. In this instance, income has no effect on grazing intensity, and the subsidy has a negative effect. If $\alpha_{G L}<1$, income has a negative effect on intensity, as does subsidy, i.e., $I^{*} / \bar{Y}^{*}<0$ and $I^{*} / \bar{S}^{*}<0$. In this instance, 
poverty reduction and subsidy are policy complements, i.e., both reduce grazing intensity. If $\alpha_{G L}>1$, income has a positive effect on intensity $\left(I^{*} / \bar{Y}^{*}>0\right)$, and the subsidy effect is ambiguous $\left(I^{*} / \bar{S}^{*} \stackrel{>}{<}\right)$. In this instance, the intended negative effect of the policy on grazing intensity is realized only if $\alpha_{G L}<\left(\frac{\beta_{S}-\alpha_{S}}{\beta_{S}}\right)$, i.e., only if the response of livestock units to grassland is sufficiently small.

\subsection{Reduced form when income is endogenous}

The foregoing analysis assumes income is unaffected by livestock numbers and grazing intensity. In reality, both variables are apt to affect income. One hypothesis, advanced by $\mathrm{Li}$ et al. (2014), is that larger farms tend to overgraze, which leads to grassland degradation and deteriorating livelihoods. Deteriorating livelihoods create a need to increase income, which causes herders to expand further their livestock. This leads to the vicious cycle depicted in Figure 1.

[Place figure 1 here]

The vicious-cycle hypothesis implies the $\gamma_{Q}$ parameter in equation (7) is positive in sign, and the $\gamma_{I}$ parameter is negative. Both of these hypotheses are tested in the empirical analysis to follow. Barring empirical evidence to the contrary, we tentatively 
assume $\gamma_{I}$ is positive, which implies higher stocking densities increase rather than decrease income, all else equal. ${ }^{3}$

With the foregoing assumptions, what hypotheses can be deduced about the effects of a change in subsidy on intensity when income is permitted to adjust? The answer is found by solving the model for the reduced form (see appendix A). The relevant equation is

$$
I^{*}=\frac{\alpha_{S}-\left(\beta_{S}+\Omega_{Q} \beta_{Y}\right)\left(1-\alpha_{G L}\right)}{1+\Omega_{I} \beta_{Y}\left(1-\alpha_{G L}\right)} \bar{S}^{*}
$$

where $\Omega_{Q}=\frac{\gamma_{Q}\left(\alpha_{G L} \beta_{S}+\alpha_{S}\right)}{1-\alpha_{G L} \beta_{Y} \gamma_{Q}}$ is the feedback effect of livestock numbers on income, and $\Omega_{I}=$ $\frac{\gamma_{I}}{1-\alpha_{G L} \beta_{Y} \gamma_{Q}}$ is the feedback effect of grazing intensity on income. Relaxing the assumption that income is exogenous complicates considerably the relationship between subsidy and intensity (compare equations (9) and (10)). Also, the signs of the feedback effects are uncertain, which means the model yields no hypotheses about the effects of subsidy on intensity. Still, the basic insight that $\alpha_{G L}$ plays a critical role in the relationship is preserved. For example, if $\alpha_{G L}=1$ equation (10) reduces to $I^{*}=\alpha_{S} \bar{S}^{*}$. In this instance, subsidy reduces intensity even in the presence of feedback effects. The same conclusion

\footnotetext{
${ }^{3}$ Harris (2010, p. 8) notes that in Chinese policy circles it is commonly assumed that a market-driven livestock sector "will function to reward conservative, and punish excessive livestock densities." However, in assessing the evidence to support this assumption, he finds it wanting. Although research suggests overstocking reduces weight gain per animal per year, it does not necessarily follow that this provides an economic incentive for pastoralists to reduce stocking rates. One reason is that, depending on how the market values animals of different weight classes, pastoralists might be able to compensate for lighter animals simply by holding and selling more of them.
} 
holds if $\alpha_{G L}<1$ and the feedback effects are non-negative, i.e., $\Omega_{Q} \geq 0$ and $\Omega_{I} \geq 0$. Whether the latter is true is an empirical issue that we address in the empirical analysis to follow.

\subsection{Effect of subsidy on income}

As noted by Li et al. (2014, p. 5), grassland restoration policies are not apt to be successful unless the basic needs and livelihoods of herders are protected. Thus, it is important to know how the subsidy affects income. The relevant equation from our theoretical model, derived in appendix $\mathrm{A}$, is

$$
Y^{*}=\frac{\Omega_{Q}+\Omega_{I}\left(\alpha_{S}-\beta_{S}\left(1-\alpha_{G L}\right)\right)}{1+\Omega_{I} \beta_{Y}\left(1-\alpha_{G L}\right)} \bar{S}^{*} .
$$

The effect of the subsidy on income cannot be predicted without additional restrictions on model parameters. Thus, whether the subsidy enhances herders' income (and thus protects livelihoods) is an empirical issue. Still, insight can be obtained by considering the special case where $\alpha_{G L}=1$. In this instance, equation (11) reduces to

$$
Y^{*}=\frac{\alpha_{S}+\beta_{S}}{\gamma_{Q}^{-1}-\beta_{Y}} \bar{S}^{*} .
$$

Subsidy increases income provided $\beta_{S}>\left|\alpha_{S}\right|$ and $\gamma_{Q}^{-1}>\beta_{Y}$. The latter condition holds whenever the responses of income to livestock numbers and grassland to income both are inelastic, i.e., whenever $\gamma_{Q}<1$ and $\beta_{Y}<1$ (sufficient condition). The former condition requires that the positive effect of the subsidy on grassland outweigh the (presumed) 
negative effect of the subsidy on livestock numbers. These are empirical issues, to which we know turn.

\section{Data and Empirical Model}

\subsection{Data}

The data were collected from randomly selected households in 70 representative villages in Inner Mongolia using the "face-to-face" quantitative household survey method. A total of 327 completed questionnaires were obtained. After cleaning the data and deleting households that: $i$ ) were ineligible for subsidy (e.g., households in the Alxa prefecture, a dessert biome), ii) had missing observations, iii) had no grassland in the surveyed year, and iv) had no livestock in both 2010 and 2012, a total of 262 households were available for analysis. ${ }^{4}$ The geographical distribution for this subset of sampled households is summarized in Table 1.

[Place table 1 here]

The five prefectures (Leagues) in Inner Mongolia can be geographically divided into three regions: the west region (Alxa), the central region (Ordos and Ulanqab), and the east region (Hulunbuir and Xilingol) (Figure 2). Within the regions, the prefectures represent distinct biomes. Specifically, Alxa locates in the desert biome, Ordos locates in both the desert and forestry biome, Ulanqab and Xinlingol locate in the grassland biome,

\footnotetext{
${ }^{4}$ In some instances missing values were replaced with sample means. Details on these and other data cleaning techniques are in an appendix available upon request from the corresponding author.
} 
and Hulunbuir locates in both the grassland and forestry biome (John et al., 2009). As noted, because households in the desert biome of Alxa did not receive subsidy, they were excluded from the analysis.

[Place figure 2 here]

\subsection{Summary statistics}

Summary statistics for the included households are shown in Table 2. The average subsidy for grassland protection across all four prefectures is $\$ 1,709$, equivalent to $22 \%$ of average household income. Fifty-three percent of the households indicated satisfaction with the subsidy policy. The average subsidy per hectare is $\$ 27.2$. In 2012 the sampled households on average had 287 sheep-equivalent livestock units and 300 hectares of grassland. The average stocking rate is 2.13 livestock units per hectare and the average income per livestock unit is $\$ 194$. The average education level of the household head is 6.8 years and the average age is 48.7 years. The average family size is 3.77 , the average number of children less than age 18 is 0.59 , and the average number of adults greater than age 64 is 0.18 . The heads of surveyed households are mostly married $(88 \%)$ and male $(87 \%)$, and their race primarily is Mongolian (74\%). Average livestock holdings between 2010 and 2012 on a sheep-equivalent basis declined slightly from 290 to 287.

[Place table 2 here]

The foregoing national averages mask significant regional variation. For example, the average subsidy per household in Hulunbuir at $\$ 2,773$ is more than double that in 
Ulanqab at $\$ 1,102$ and Ordos at $\$ 1,217$. Income per livestock unit ranges from $\$ 25$ in Hulunbuir to $\$ 704$ in Ulanqab. Livestock units per household in Hulunbuir are 4.8 times higher than in Ordos (636 versus 132). The stocking rate (livestock units/hectare) ranges from 1.71 in Hulunbuir to 3.88 in Ulanqab. This compares to 1.3 sheep per hectare suggested by Wang (2000) and Liu et al. (2004) as the upper safe limit. Other research suggests this safe limit can be extended by grazing a mixture of species (not just sheep), and by seasonal grazing (Yu et al., 2004). Although the optimal carrying capacity has yet to be clarified (Harris 2010), the average stocking rate of 2.13 across the four prefectures suggests overgrazing might be an issue for the studied households.

\subsection{Empirical model}

The parameters of the theoretical model are estimated using the following econometric specification:

$$
\begin{gathered}
\ln Q_{i}^{2012}=a_{0}+\sum_{j=2}^{4} a_{j} \cdot D_{j, i}+a_{S} \ln S_{i}+\sum_{j=2}^{4} a_{S X D j} \ln S_{i} \cdot D_{j, i} \\
\quad+a_{S X S A T} \ln S_{i} \cdot \text { SATIS }_{i}+a_{G L} \ln G L_{i}+a_{Q L A G} \ln Q_{i}^{2010}+e_{i}
\end{gathered}
$$

(14) $\ln G L_{i}=b_{0}+\sum_{j=2}^{4} b_{j} \cdot D_{j, i}+b_{S} \ln S_{i}+\sum_{j=2}^{4} b_{S X D j} \ln S_{i} \cdot D_{j, t}+b_{S x S A T} \ln S_{i} \cdot S A T I S_{i}$

$$
+b_{Y} \ln Y_{i}+b_{D I S T} D I S T A N C E_{i}+b_{R} R A C E_{i}+u_{i}
$$

(15) $\ln Y_{i}=c_{0}+\sum_{j=2}^{4} c_{j} D_{j, t}+c_{Q} \ln Q_{i}^{2012}+c_{I} \ln \left(Q_{i}^{2012} / G L_{i}\right)+c_{A G E} \ln A G E_{i}+c_{E D} E D U C_{i}$

$$
+c_{R} R A C E_{i}+v_{i}
$$


where $Q_{i}^{2012}\left(Q_{i}^{2010}\right)$ is the quantity of sheep-equivalent livestock units owned by household $i$ in $2012(2010) ;{ }^{5} G L_{i}$ is the grassland controlled by household $i$ measured in hectares; $Y_{i}$ is total income received by household $i$ in 2012 measured in U.S. dollars; $D_{j, i}$ are dummy variables to indicate the geographic location of household $i$ (Ordos $\left(\mathrm{D}_{2}\right)$, Ulanqab $\left(\mathrm{D}_{3}\right)$, and Hulunbuir $\left(\mathrm{D}_{4}\right)$, with Xinlin Gol $\left(\mathrm{D}_{1}\right)$ as the excluded category); $S_{i}$ is the grassland protection subsidy received by household $i$ in 2012 measured in U.S. dollars; $\operatorname{SATIS}_{i}$ is a dummy variable to indicate whether household $i$ is satisfied with the subsidy policy $\left(\operatorname{SATIS}_{i}=1\right.$ if yes, $0=$ no); $\operatorname{DISTANCE}_{i}$ is a categorical variable indicating the distance of household $i$ to the nearest city center $(1=$ within 10 kilometers, $2=10-30 \mathrm{~km}$, $3=31-80 \mathrm{~km}, 4=81-150 \mathrm{~km}$, and $5=$ greater than $150 \mathrm{~km}$ ); $R A C E_{i}$ is a dummy variable to indicate the race of household $i(1=$ Mongolian, $0=$ others $) ; A G E_{i}$ is the age of the head of household $i$ measured in years; $E D U C_{i}$ is the education level of the head of household $i$ measured in years; and $e_{i}, u_{i}$ and $v_{i}$ are random disturbance terms.

Equations (13) - (15) are expressed in double-log form so that the parameters may be interpreted as elasticities. The exceptions are $\operatorname{DISTANCE}_{i}$ and $E D U C_{i}$, which enter linearly, the former due to its categorical definition $(1,2, \ldots, 5)$, the latter to permit assessment of the effect of an additional year of education on income. A lagged dependent variable is included in equation (13) to account for possible delays in the

\footnotetext{
${ }^{5}$ Sheep Equivalent Livestock Units were calculated using the following conversions: 1 cattle or mule $=5$ sheep; 1 horse $=6$ sheep; 1 camel $=7$ sheep; 1 donkey $=3$ sheep; 1 pig $=1.5$ sheep; 1 chicken $=0.05$ sheep (Li and Ji, 2014).
} 
adjustment of livestock units to changes in grassland and subsidy. If $a_{L A G}=0$, adjustment is instantaneous and the estimated parameters of the grassland and subsidy variables in equation (13) are interpreted as long-run elasticities. If $0<a_{L A G}<1$, adjustment is not instantaneous and the long-run elasticities are obtained by dividing the estimated parameters of equation (13) by one minus the estimated coefficient of the lagged dependent variable (Nerlove, 1956; Cuddington and Dagher, 2015). Interaction terms are included in equations (13) and (14) to test whether the response of livestock units and grassland to subsidy differs across geographical regions or with satisfaction with subsidy policy. Race is included as a control variable in equations (14) and (15) to test whether discrimination exists in the letting of land contracts or in income determination. Distance is included in equation (14) to test the extent to which proximity to a city center affects grassland holdings. Education and age are included in equation (15) to test the extent to which human capital matters in the income earning potential of pastoralists.

\section{Regression results}

\subsection{Estimation procedures}

The empirical model contains right-hand-side variables that are endogenous. Consequently, to avoid simultaneous-equation bias the equations are estimated using the Generalized Method of Moments (GMM) estimator. There are three endogenous variables in the model: $Q_{i}^{2012}, G L_{i}$, and $Y_{i}$. The remaining variables in equations (13) - (15) are exogenous and thus serve as instruments in the GMM procedure. To ensure that the 
number of instruments is sufficient to satisfy the order condition for identification, the instrument list was augmented with the following variables listed in Table 2: Family Size, Children $<18$, Older Adults, Married, and Male. Zero values for subsidy and livestock were set to 1 to permit taking logarithms. To assess the potential importance of simultaneous-equation bias, and to determine the robustness of results to estimation procedure, the model also is estimated by OLS. Unless indicated otherwise, statistical significance is determined using a two-tail $t$-test at the $5 \%$ probability level.

\subsection{Estimation results}

Results are satisfactory in that most of the signs of the estimated coefficients agree with a priori expectations, and most are significant (Table 3 ). The $R^{2} \mathrm{~s}$ range from 0.33 to 0.52 depending on equation and estimation procedure, which suggests the model has good explanatory power given the cross-section nature of the data. The J-statistic for the GMM estimates is not significant in any of the equations, which suggests the instruments are valid. The results are robust to estimation procedure in that signs of the estimated coefficients are unaffected.

[Place table 3 here]

The most important difference between the OLS and GMM estimates is in the statistical significance of the Race variable in the income equation and in the interaction terms for subsidy in the livestock and grassland equations. In the grassland equation, none of the interaction terms is significant in the GMM estimates, while one of the terms 
(Subsidy $\times \mathrm{D}_{3}$ ) is significant at the $10 \%$ level in the OLS estimates. In the livestock equation, all three of the interaction terms for region are significant in the GMM estimates, while only one (Subsidy $\times \mathrm{D}_{2}$ ) is significant in the OLS estimates. In the income equation, Race is significant in the GMM estimates, but not in the OLS estimates. Overall, correcting for simultaneous-equation bias is important in that without the correction Race has no effect on income when in fact it has a negative effect. Also, interaction effects would appear to be unimportant in the livestock equation and important in the grassland equation, when in fact the opposite is true. The remaining discussion will be confined to the GMM estimates.

\subsubsection{Livestock equation}

Focusing first on the equation for livestock, the estimated coefficient of the lagged dependent variable (Livestock_2010) is $0.527(t$-ratio $=6.46)$. Thus, the static model is rejected and long-run coefficients may be obtained by dividing the estimated short-run coefficients in the equation by $1-0.527=0.473$. This estimate suggests it takes 2.5 years for livestock numbers to achieve $80 \%$ adjustment to the new equilibrium following a onetime change in the subsidy, and 4.7 years to achieve $95 \%$ adjustment. $^{6}$

\footnotetext{
${ }_{6}$ The adjustment periods are computed using the formula $\left(\hat{\alpha}_{L A G}\right)^{T}=(1-X / 100)$ where $\widehat{\alpha}_{\mathrm{LAG}}$ is the estimated coefficient of the lagged dependent variable in equation (9), and $T$ the number of years it takes to achieve $X \%$ adjustment to the new equilibrium. For a good recent discussion of lagged dependent variable models, their implied dynamics, and limitations, see Cuddington and Dagher (2015).
} 
Of the five variables for subsidy included in the model, all but one is significant at the $10 \%$ level or better. The insignificant variable is Subsidy $x$ Satisfied. Whether or not a household is satisfied with the subsidy has no effect on the subsidy's ability to influence livestock units. The estimated coefficients for the remaining subsidy terms Subsidy, Subsidy $x D_{2}$, Subsidy $x D_{3}$, and Subsidy $x D_{4}$ respectively are $-0.136,0.274,0.139$, and 0.131 . An isolated 1\% increase in subsidy decreases the livestock units held by households in Xilingol and Hulunbuir by $0.136 \%$ and $0.005 \%$, respectively; and increases livestock units held by households in Ulanqab and Ordos by $0.138 \%$ and $0.003 \%$, respectively. These are short-run (one year) effects. The long-run ( 4.7 year) effects are obtained by dividing the short-run effects (elasticities) by 0.473 to yield $-0.288,0.292,0.006$, and -0.011 as the response of livestock units to subsidy in Xilingol, Ulanqab, Ordos, and Hulunbuir, respectively.

Turning to $a_{G L}$, a key parameter from a policy perspective, its estimated short-run value is $0.226(t$-ratio $=1.71)$ and its estimated long-run value is $0.478(t$-ratio $=2.11) .{ }^{7}$ An isolated 1\% increase in grassland increases livestock units by $0.226 \%$ in the short run and $0.478 \%$ in the long run. Importantly, both the short- and long-run estimates of $\alpha_{G L}$ are less than 1 . Hence, the sufficient condition for an increase in subsidy to reduce grazing

\footnotetext{
${ }^{7}$ The $t$-ratio for the long-run estimate is computed by applying the delta method to $\hat{\alpha}_{G L}^{l r}=\hat{\alpha}_{G L}^{S r} /\left(1-\hat{\alpha}_{L A G}\right)$ where $\hat{\alpha}_{G L}^{S r}=0.226$ and $\hat{\alpha}_{L A G}=0.527$, the GMM estimates of these parameters reported in table 3 .
} 
intensity is satisfied (assuming feedback effects of livestock numbers and grazing intensity on income are non-negative)

\subsubsection{Grassland equation}

The estimated coefficient for subsidy in the grassland equation is $0.335(t$-ratio $=$ 2.17). Since none of the interaction terms for subsidy is significant, this coefficient is interpreted as applying to all four regions. An isolated 1\% increase in subsidy increases the household's holdings of grassland by $0.335 \%$ in each of the four prefectures. Income, distance, and race all have positive effects on grassland. The estimated coefficient of income, namely $0.786(t$-ratio $=5.85)$, suggests an isolated $1 \%$ increase in household income increases grassland holdings by $0.786 \%$. The estimated coefficient of Race is 0.526 $(t$-ratio $=3.15)$, which suggests a Mongolian household has $52.6 \%$ more grassland than a non-Mongolian household, all else equal.

The distance variable, which enters linearly due to its categorical nature, has an estimated coefficient of $0.179(t$-ratio $=1.94)$. An isolated one unit increase in distance to the nearest city center increases the household's holdings of grassland by $17.9 \%$. The sample mean of the distance variable is 2.87. A value of 3 for this variable means that the household is between 31 and 80 kilometers from the city center and a value of 4 means the household is between 81 and 150 kilometers distant. Using midpoints of these intervals, an increase from 3 (the approximate sample mean) to 4 in the distance variable equates to a 60 kilometer increase in distance to the city center. That grassland holdings 
tend to increase with distance to the city center suggests the advantages of being close to market are outweighed by the higher land rents associated with urban settings.

\subsubsection{Income equation}

Income is positively related to livestock units and education and negatively related to grazing intensity and race. The estimated coefficient of Race is -0.325 ( $t$-ratio $=-1.94)$. Households of the Mongolian race have $32.5 \%$ less income than non-Mongolian households, all else equal. The estimated coefficient of Education is $0.046(t$-ratio $=2.88)$. Household income increases by $4.6 \%$ for each additional year of education, all else equal. The estimated coefficient for livestock is $0.851(t$-ratio $=10.2)$. An isolated $1 \%$ increase in sheep-equivalent livestock units increases household income by $0.851 \%$. The estimated coefficient of grazing intensity is $-0.375(t$-ratio $=-2.65)$. An isolated $1 \%$ increase in grazing intensity reduces household income by $0.375 \%$. This last result contradicts our assumption in the theoretical model that income is positively related to grazing intensity. A negative relationship between income and intensity is consistent with the overgrazing hypothesis. It suggests the surveyed households have an economic incentive to reduce intensity.

\section{Reduced-form elasticities}

The empirical analysis indicates subsidy increases grassland holdings, and has a mixed effect on livestock numbers depending on region. Combining these results, what can be said about the effect of the subsidy on grazing intensity, and, more generally, on 
household income? To answer the question, we computed reduced-form elasticities for subsidy using the matrix equation derived in Appendix B. Reduced-form elasticities tell the effect of subsidy on intensity taking into account its indirect effect on income. They are computed by inserting into the matrix equation empirical estimates of the model's structural parameters as summarized in table 4 . The values for $\alpha_{G L}$ and $\alpha_{S}$ given in Table 4 are the long-run (as opposed to short-run) estimates. Thus, the reduced-form elasticities properly are interpreted as long-run effects, i.e., effects within five years after a change in the subsidy. Since education can be thought of as a policy instrument, we also compute reduced-form elasticities for this variable for comparison purposes.

[Place table 4 here]

\subsection{Effect of subsidy on grazing intensity}

Results suggest the policy was effective in that the reduced-form elasticity of intensity with respect to subsidy is negative across all four prefectures (Table 5). The effects, however, are uneven. Xilingol shows the strongest response at -0.532 and Ulanqab the weakest at -0.168 . The relative unresponsiveness of Ulanqab is noteworthy in that its stocking rate at 3.88 is, by far, the highest among the studied prefectures (see Table 2), and thus would appear to be most in need of reduction. One explanation for the weak response might be flaws in policy design or implementation. Only $29 \%$ of the surveyed households in Ulanqab indicated satisfaction with the policy compared to $81 \%$ 
in Hulunbuir (Table 2). Investigation of the sources of dissatisfaction might yield useful insight into how to improve the policy going forward.

[Place table 5]

The responses of intensity to subsidy in Ordos and Hulunbuir are about equal at 0.348 and -0.358 , respectively. Given that the subsidy rate in Hulunbuir (0.47) is over three times that in Ordos $(0.13$, see Table 2$)$, these estimates suggest the subsidy rate per se has little effect on subsidy effectiveness. That is, throwing money at the problem is not the answer to improved policy effectiveness.

\subsection{Effect of education on grazing intensity}

Turning to education, results suggest education and subsidy are policy complements in that both reduce intensity. Specifically, each additional year of education is associated with a $3.6 \%$ reduction in intensity across the four prefectures. By way of comparison, each additional $1 \%$ increase in subsidy is associated with a $0.168 \%$ to $0.532 \%$ reduction in intensity depending on prefecture. Consequently, to get a $3.6 \%$ reduction in intensity, subsidy would need to be increased by between $6.8 \%$ and $21.4 \%$. Thus, for example, if the goal of government is to reduce grazing intensity by $3.6 \%$, it could do so by raising the education level of pastoralists by 1 year, or, alternatively, by increasing subsidy by $6.8 \%$ in Xilingol, $10.1 \%$ in Hulunbuir, $10.3 \%$ in Ordos, and $21.4 \%$ in Ulanqab. An additional year of education is equivalent to a $10 \%$ increase in subsidy in Hulunbuir 
and Ordos, a $7 \%$ increase in Xilingol, and a 21\% increase in Ulanqab in terms of its effectiveness in reducing grazing intensity.

\subsection{Income effects}

As noted by Li et al. (2014), for conservation policies to be effective they cannot reduce herders' standard of living. Thus, it is critical to know the effect of the subsidy on herders' income. The reduced-form elasticities of income with respect to subsidy are positive across all four prefectures (Table 5). Subsidy is most effective at raising income in Ulanqab (0.670) and least effective in Xilingol (0.144). The region in which the policy is the least (most) effective at reducing grazing intensity is also the region in which it is the most (least) effective at raising income. Thus, the relative ineffectiveness of the policy in reducing grazing intensity in Ulanqab cannot be ascribed to a deleterious effect on income: income in Ulanqab not only rose in response to the subsidy, but did so at a faster rate than in the other prefectures, including Ordos where the subsidy rate $(0.13)$ is the same as in Ulanqab. Overall, the positive effect of the subsidy on income suggests the policy is sustainable, i.e., it ameliorates rather than acerbates the vicious cycle depicted in Figure 1.

Each additional year of education increases herders' income $8.7 \%$. The reducedform or "total" effect (0.087) is nearly twice as large as the "partial" effect (0.046) estimated in the econometric model (see table 3, last column). The reason for this is that the total effect takes into account the positive effect that education has on livestock 
numbers. This may be seen by writing the income equation in the abbreviated form $Y=$ $f\left(\overline{E D}, Q\left(G L(Y(\overline{E D}))\right.\right.$ and taking its derivative with respect to education to yield $\frac{\partial Y}{\partial \overline{E D}}=$ $\frac{\partial f}{\partial \overline{E D}}+\frac{\partial f}{\partial Q} \frac{\partial Q}{\partial G L} \frac{\partial G L}{\partial Y} \frac{\partial Y}{\partial \overline{E D}}$. The effect of a change in education on income can be decomposed into a direct effect $\frac{\partial f}{\partial \overline{E D}}>0$ that reflects the benefits of increased human capital on earning capacity, and an indirect effect $\frac{\partial f}{\partial Q} \frac{\partial Q}{\partial G L} \frac{\partial G L}{\partial Y} \frac{\partial Y}{\partial \overline{E D}}>0$ that reflects the benefits of education on the household's ability to afford grassland, which in turn affects livestock numbers, which in turn affects income. The econometric estimate of education's effect on income ignores the indirect effect, and thus understates its actual effect.

The reduced-form estimates suggest three years of high school might enhance household income by $26 \%$ while at the same time reducing grazing intensity by $11 \%$. Clearly, education is not to be overlooked as a policy tool for ecosystem preservation.

\subsection{Sensitivity analysis}

The theoretical analysis identified the production elasticity $\alpha_{G L}$ as a critical parameter. Thus, it is of some interest to know the extent to which this parameter affects inferences. To determine that, we computed the reduced-form elasticities for subsidy using alternative values of $\alpha_{G L}$ as shown in Table 6. Specifically, we set $\alpha_{G L}$ alternatively to 0.036 and 0.920 , the limits of the $95 \%$ confidence interval for the long-run estimate of this parameter based on the GMM estimates in Table 3. 
Results are robust in that the magnitude but not the direction of the effects are affected. For example, the signs of $G L^{*} / S^{*}$ and $Y^{*} / S^{*}$ are uniformly positive for the considered values of $\alpha_{G L}$. Increases in subsidy increases grassland and income in all regions. The only instance in which signs are affected is for $Q^{*} / S^{*}$ in the case of Xilingol, and for $I^{*} / S^{*}$ in the case of Ulanqab. In these instances, increasing $\alpha_{G L}$ from its point estimate of 0.478 to 0.920 causes the effect of subsidy on livestock numbers in Xilingol to switch from negative to positive, and the effect of subsidy on intensity in Ulanqab to switch from negative to positive. The upshot is that while one can be confident that the subsidy reduced grazing intensity in Xilingol, Ordos, and Hulunbuir, some caution must be exercised in making the same claim for Ulanqab, as the sign of the effect for this prefecture is sensitive to empirically-legitimate values for $\alpha_{G L}$.

[Place table 6 here]

\subsection{Financial implications}

Suppose the goal is to cut grazing intensity to 1.3 sheep-equivalent units per hectare. By how much would subsidy need to be increased to achieve this goal? To address the question, we applied the relevant reduced-form elasticities in Table 5 to the sample data on stocking rates and subsidy levels as shown in Table 7. Results suggest to achieve the goal, subsidy would need to be increased by between $50 \%$ and $396 \%$, which equates to an added cost per hectare of between $\$ 5.7$ and $\$ 51.9$. The goal is achieved most cheaply in Hulunbuir and most expensively in Ulanqab. The high cost for Ulanqab (\$51.9 
per hectare) is due to its relative unresponsiveness to subsidy, but also to its large gap between the targeted and actual intensity (1.30 versus 3.88 livestock units per hectare). Households in Hulunbuir by far have the largest holdings of grassland (636 hectares versus a sample average of 300), which may explain in part the relatively low cost (per hectare) of achieving the policy target in this prefecture.

The added costs of achieving a $1 \%$ reduction in intensity is $\$ 0.2 /$ ha for Hulunbuir, $\$ 0.3 /$ ha for Ordos, $\$ 0.5 /$ ha for Xilingol and $\$ 0.8 /$ ha for Ulanqab. If the budget is constrained, diverting funds from Ulanqab to Hulunbuir or Ordos might improve the efficiency of the policy in terms of its ability to reduce stocking density. Absent identification and correction of Ulanqab's weak response to the subsidy, increased spending in this prefecture would not be cost effective (if the goal is to reduce grazing intensity).

\section{Conclusions and discussion}

This paper examines the effect of grassland protection programs on grazing intensity in Inner Mongolia. Using household survey data collected in 2013, we attempt to understand the grassland, livestock, and herders' income responses to a subsidy provided by the Chinese government to encourage conservation practices. The results of statistical analysis suggest the subsidy increased the grassland controlled by the household, and the effect was uniform across the four studied prefectures. The effect of the subsidy on livestock numbers, however, was mixed, with Xilingol and Hulunbuir 
showing negative responses, and Ulanqab and Ordos showing positive responses. Statistical estimates of the income equation suggest larger livestock holdings increase income, as does education, while increased grazing intensity (stocking rate) reduces income, all else equal.

The effects of the subsidy on grazing intensity (defined as the ratio of sheepequivalent livestock units to grassland) were determined by solving the structural model for the reduced form. The reduced form indicates the net effect of the subsidy on intensity, i.e., the effect that takes into account the induced effect of a change in subsidy on income. Results suggest the subsidy reduced grazing intensity in three of the four studied prefectures, namely Xilingol, Ordos, and Hulunbuir. The reduced-form elasticities in these prefectures range from -0.35 to -0.53 , which suggests each $1 \%$ increase in subsidy reduces grazing intensity in these prefectures by between $0.35 \%$ and $0.53 \%$. There is also a negative effect indicated for Ulanqab, but the reduced-form elasticity is small $(-0.168)$, and its sign is sensitive to assumed values for a key parameter in the model.

A critical issue for conservation policies is their effect on herders' income. Our analysis indicates reduced grazing intensity is not incompatible with increased income from subsides. Specifically, the reduced-form elasticities of income with respect to subsidy across all four prefectures are positive. They range from 0.144 for Xilingol to 0.670 for Ulanqab, which means a $1 \%$ increase in subsidy increases household income by 
between $0.144 \%$ and $0.67 \%$ depending on prefecture. These results suggest the subsidy ameliorates rather than acerbates the vicious cycle depicted in Figure 1.

To gauge the relative effectiveness of subsidy, we computed reduced-form effects for education. Results suggest each additional year of education increases herders' income by $8.7 \%$ and reduces grazing intensity by $3.6 \%$. These estimates suggest 3 years of high school might increase income by $26 \%$ and reduce grazing intensity by $11 \%$. Thus, education should not be overlooked as a policy tool for advancing conservation goals.

To the extent reduced stocking rates contribute to grassland restoration, as suggested in a number of studies (e.g., Purvis and Curry, 1981; Agarwal et al., 1993; Katoh et al.,1998; Wakeham-Dawson et al., 1998; Smart and Coutts, 2004; Cole et al., 2007; Rasran et al., 2007), our analysis suggests the subsidy aspect of China's grassland restoration policy as it applies to Inner Mongolia is working. However, effectiveness is uneven, with some prefectures showing a larger response than others. Only one prefecture, namely Xilingol, showed a negative relationship between livestock numbers and subsidy, and even then the negative relationship was not robust. This suggests compliance monitoring may need to be strengthened if the policy is to be fully effective.

Our field work suggests many herdsmen fail to follow policy requirements after obtaining the subsidy. The government usually releases the subsidy to herdsmen before implementation of the grassland protection policy each year. A better approach might be to delay payments until it has been confirmed that grazing control measures have been 
followed. More importantly, an effective monitoring system should be established. An official database consisting of livestock numbers, grassland condition, and other relevant indicators might help ensure compliance.

Forty-seven percent of the surveyed households indicated they were not satisfied with the grassland protection policies as currently implemented. In Ulanqab the dissatisfaction rate was $71 \%$. Additional research is needed to determine the source of the dissatisfaction, and to identify strategies to increase herdsmen participation and to improve compliance with program restrictions. 
Acknowledgements: Major support for this research came from the U.S. National Science Foundation - Dynamics of Coupled Natural and Human Systems (NSF-CNH program \#1523628), the Economy and Environment Program for Southeast Asia (EEPSEA), , and the Alabama Agricultural Experiment Station, Auburn University. 
Fig. 1. Vicious cycle in increasing herder's income (Source: Li et al. 2014)
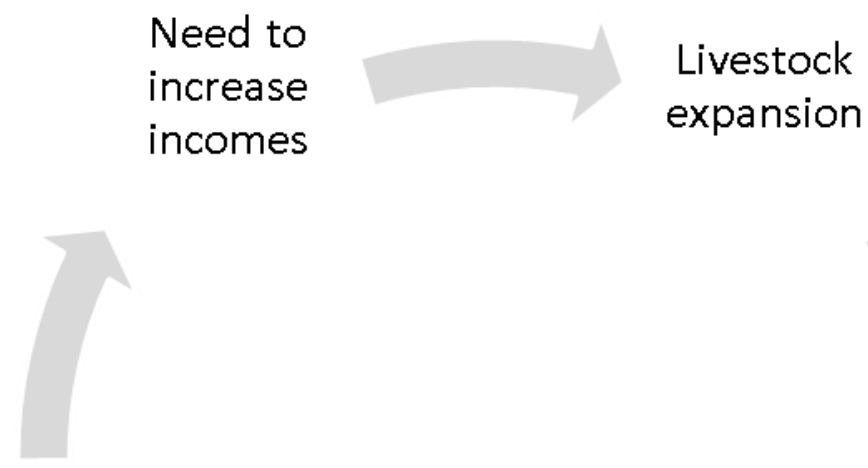

incomes

Deteriorating

livelihoods

Grassland

degradation

Stock output

reduction 
Fig. 2. Distribution of surveyed areas in Inner Mongolia

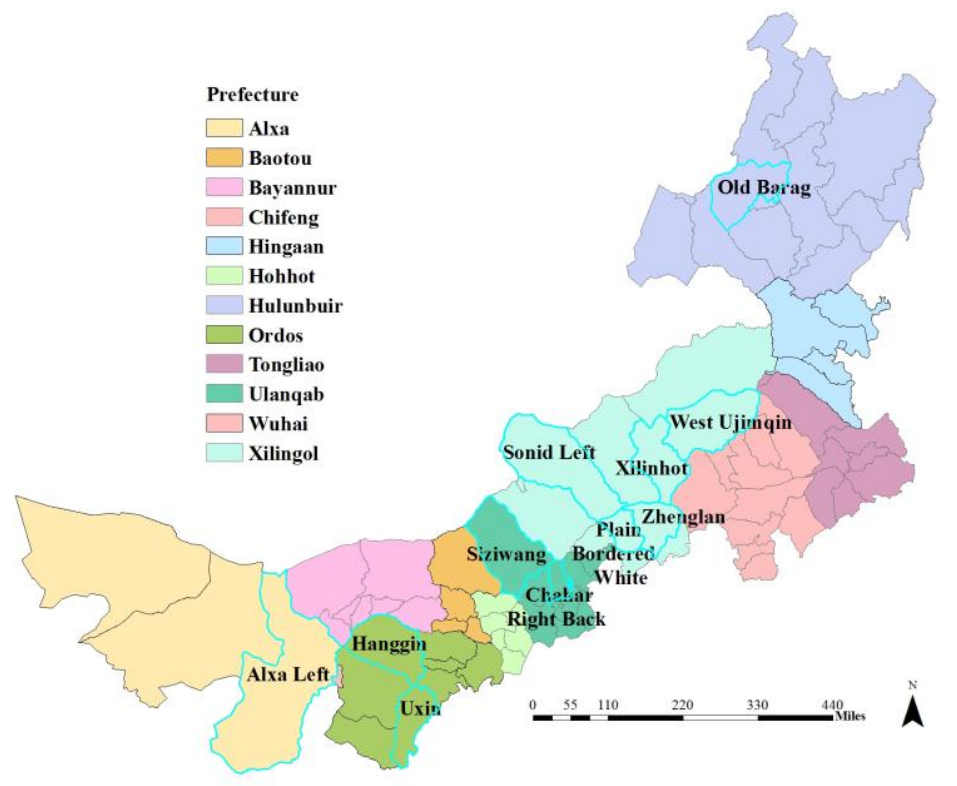

Data source: authors' field work in Inner Mongolia in 2013. 


\section{Table 1}

Geographical distribution of sample households

\begin{tabular}{llc}
\hline Prefecture & County & Sample \\
\hline Xilingol & Xilinhot, West Ujimqin Banner, Plain and Bordered White & 134 \\
& Banner, Zhenlan Banner, Sonid Left Banner & \\
Ulanqab & Siziwang Banner, Chahar Right Back Banner & 40 \\
Ordos & Hanggin Banner, Uxin Banner & 61 \\
Hulunbuir & Old Barag Banner & 27 \\
All & -- & 262
\end{tabular}

Data source: authors' field work in 2013. 
Table 2

Summary statistics of survey data used to estimate the model, Inner Mongolia, 2012

\begin{tabular}{|c|c|c|c|c|c|}
\hline \multirow[b]{2}{*}{ Variable } & \multicolumn{5}{|c|}{ Prefecture } \\
\hline & Xilingol & Ulanqab & Ordos & Hulunbuir & All \\
\hline Observations $(\mathrm{N})$ & 134 & 40 & 61 & 27 & 262 \\
\hline Subsidy (USD) & $\begin{array}{c}1,900 \\
(1,824)^{\mathrm{a}}\end{array}$ & $\begin{array}{c}1,102 \\
(1,122)\end{array}$ & $\begin{array}{c}1,217 \\
(1.015)\end{array}$ & $\begin{array}{c}2,773 \\
(1,458)\end{array}$ & $\begin{array}{c}1,709 \\
(1,606)\end{array}$ \\
\hline Satisfaction $\mathrm{w} /$ subsidy & $\begin{array}{c}0.56 \\
(0.49)\end{array}$ & $\begin{array}{c}0.29 \\
(0.45)\end{array}$ & $\begin{array}{c}0.49 \\
(0.51)\end{array}$ & $\begin{array}{c}0.81 \\
(0.40)\end{array}$ & $\begin{array}{c}0.53 \\
(0.49)\end{array}$ \\
\hline Income (USD) & $\begin{array}{c}15,325 \\
(18,753)\end{array}$ & $\begin{array}{c}14,034 \\
(11,840)\end{array}$ & $\begin{array}{c}19,522 \\
(21,817)\end{array}$ & $\begin{array}{l}12,355 \\
(8,540)\end{array}$ & $\begin{array}{c}15,799 \\
(17,941)\end{array}$ \\
\hline Subsidy rate & $\begin{array}{c}0.23 \\
(0.32)\end{array}$ & $\begin{array}{c}0.13 \\
(0.15)\end{array}$ & $\begin{array}{c}0.13 \\
(0.16)\end{array}$ & $\begin{array}{c}0.47 \\
(0.84)\end{array}$ & $\begin{array}{c}0.22 \\
(0.38)\end{array}$ \\
\hline Livestock in 2010 & $\begin{array}{c}272 \\
(289)\end{array}$ & $\begin{array}{c}254 \\
(179)\end{array}$ & $\begin{array}{c}217 \\
(116)\end{array}$ & $\begin{array}{c}599 \\
(515)\end{array}$ & $\begin{array}{c}290 \\
(297)\end{array}$ \\
\hline Livestock in 2012 & $\begin{array}{c}238 \\
(289)\end{array}$ & $\begin{array}{c}358 \\
(1,056)\end{array}$ & $\begin{array}{c}222 \\
(130\end{array}$ & $\begin{array}{c}572 \\
(450)\end{array}$ & $\begin{array}{c}287 \\
(494)\end{array}$ \\
\hline Grassland (hectare) & $\begin{array}{c}337 \\
(630)\end{array}$ & $\begin{array}{c}205 \\
(207)\end{array}$ & $\begin{array}{l}132 \\
(65)\end{array}$ & $\begin{array}{c}636 \\
(1,613)\end{array}$ & $\begin{array}{c}300 \\
(700)\end{array}$ \\
\hline Stocking rate (2012) & $\begin{array}{c}1.77 \\
(1.79)\end{array}$ & $\begin{array}{c}3.88 \\
(11.6)\end{array}$ & $\begin{array}{c}1.98 \\
(1.45)\end{array}$ & $\begin{array}{c}1.71 \\
(1.13)\end{array}$ & $\begin{array}{c}2.13 \\
(4.84)\end{array}$ \\
\hline Income/Livestock (2012) & $\begin{array}{c}83 \\
(69)\end{array}$ & $\begin{array}{c}704 \\
(2,598)\end{array}$ & $\begin{array}{c}181 \\
(516)\end{array}$ & $\begin{array}{c}25 \\
(14)\end{array}$ & $\begin{array}{c}194 \\
(1,058)\end{array}$ \\
\hline Subsidy/Grassland (\$/ha) & $\begin{array}{c}24.5 \\
(35.4)\end{array}$ & $\begin{array}{c}13.1 \\
(14.9)\end{array}$ & $\begin{array}{c}9.7 \\
(8.5)\end{array}$ & $\begin{array}{c}5.8 \\
(3.5)\end{array}$ & $\begin{array}{c}17.6 \\
(27.2)\end{array}$ \\
\hline Distance to city center & $\begin{array}{c}3.10 \\
(1.00)\end{array}$ & $\begin{array}{c}3.05 \\
(0.93)\end{array}$ & $\begin{array}{c}2.21 \\
(0.86)\end{array}$ & $\begin{array}{c}2.89 \\
(0.70)\end{array}$ & $\begin{array}{c}2.87 \\
(0.99)\end{array}$ \\
\hline Education & 7.11 & 6.10 & 6.84 & 6.25 & 6.80 \\
\hline & & 34 & & & \\
\hline
\end{tabular}




\begin{tabular}{|c|c|c|c|c|c|}
\hline & $(3.48)$ & $(2.73)$ & $(2.92)$ & $(2.95)$ & $(3.21)$ \\
\hline Age & $\begin{array}{c}46.7 \\
(10.7)\end{array}$ & $\begin{array}{c}50.0 \\
(10.5)\end{array}$ & $\begin{array}{l}52.0 \\
(9.9)\end{array}$ & $\begin{array}{l}49.1 \\
(5.8)\end{array}$ & $\begin{array}{c}48.7 \\
(10.3)\end{array}$ \\
\hline Family size & $\begin{array}{c}3.78 \\
(1.15)\end{array}$ & $\begin{array}{c}3.53 \\
(1.13)\end{array}$ & $\begin{array}{c}3.90 \\
(1.27)\end{array}$ & $\begin{array}{c}3.78 \\
(1.15)\end{array}$ & $\begin{array}{c}3.77 \\
(1.18)\end{array}$ \\
\hline Children $(<18)$ & $\begin{array}{c}0.64 \\
(0.71)\end{array}$ & $\begin{array}{c}0.50 \\
(0.510\end{array}$ & $\begin{array}{l}(0.51) \\
(0.60)\end{array}$ & $\begin{array}{c}0.67 \\
(0.73)\end{array}$ & $\begin{array}{c}0.59 \\
(0.66)\end{array}$ \\
\hline Older Adults (>64) & $\begin{array}{c}0.15 \\
(0.42)\end{array}$ & $\begin{array}{c}0.18 \\
(0.450\end{array}$ & $\begin{array}{c}0.26 \\
(0.66)\end{array}$ & $\begin{array}{c}0.11 \\
(0.42)\end{array}$ & $\begin{array}{c}0.18 \\
(0.49)\end{array}$ \\
\hline Married & $\begin{array}{c}0.85 \\
(0.36)\end{array}$ & $\begin{array}{c}0.90 \\
(0.30)\end{array}$ & $\begin{array}{c}0.95 \\
(0.22)\end{array}$ & $\begin{array}{c}0.81 \\
(0.40)\end{array}$ & $\begin{array}{c}0.88 \\
(0.33)\end{array}$ \\
\hline Male & $\begin{array}{c}0.88 \\
(0.33)\end{array}$ & $\begin{array}{c}0.93 \\
(0.27)\end{array}$ & $\begin{array}{c}0.79 \\
(0.41)\end{array}$ & $\begin{array}{c}0.93 \\
(0.27)\end{array}$ & $\begin{array}{c}0.87 \\
(0.34)\end{array}$ \\
\hline Race & $\begin{array}{c}0.77 \\
(0.42)\end{array}$ & $\begin{array}{c}0.48 \\
(0.51)\end{array}$ & $\begin{array}{c}0.75 \\
(0.43)\end{array}$ & $\begin{array}{c}0.96 \\
(0.19)\end{array}$ & $\begin{array}{c}0.74 \\
(0.44)\end{array}$ \\
\hline
\end{tabular}

aNumber in parenthesis is standard deviation. 
Table 3

Regression estimates of the empirical model $(\mathrm{N}=262)$

\begin{tabular}{|c|c|c|c|c|c|c|c|c|c|c|c|c|}
\hline \multirow{3}{*}{$\begin{array}{l}\text { Variable/ } \\
\text { Statistic }\end{array}$} & \multicolumn{6}{|c|}{ OLS } & \multicolumn{6}{|c|}{ GMM } \\
\hline & \multicolumn{2}{|c|}{ Livestock_2012 } & \multicolumn{2}{|c|}{ Grassland } & \multicolumn{2}{|c|}{ Income } & \multicolumn{2}{|c|}{ Livestock_2012 } & \multicolumn{2}{|c|}{ Grassland } & \multicolumn{2}{|c|}{ Income } \\
\hline & Coef. & $t$-ratio & Coef. & $t$-ratio & Coef. & $t$-ratio & Coef. & $t$-ratio & Coef. & $t$-ratio & Coef. & $t$-ratio \\
\hline Subsidy & $-0.166^{* *}$ & -2.12 & $0.318^{* *}$ & 3.62 & -- & -- & $-0.136^{* *}$ & -2.38 & $0.355^{* *}$ & 2.17 & - & -- \\
\hline Subsidy $x \mathrm{D}_{2}$ & $0.303^{* *}$ & 2.66 & -0.056 & -0.42 & -- & -- & $0.274^{*}$ & 1.85 & -0.126 & -0.60 & -- & -- \\
\hline Subsidy $x \mathrm{D}_{3}$ & 0.153 & 1.42 & $-0.216^{*}$ & -1.74 & -- & -- & $0.139^{* *}$ & 2.33 & -0.270 & -1.63 & -- & -- \\
\hline Subsidy $x \mathrm{D}_{4}$ & 0.154 & 1.19 & -0.213 & -1.42 & -- & -- & $0.131^{* *}$ & 2.19 & -0.253 & -1.50 & -- & -- \\
\hline Subsidy $x$ Satisfied & -0.001 & -0.057 & 0.001 & 0.04 & -- & -- & 0.000 & 0.01 & 0.009 & 0.39 & -- & -- \\
\hline Grassland & $0.374^{* *}$ & 7.51 & -- & -- & -- & -- & $0.226^{*}$ & 1.71 & -- & -- & -- & -- \\
\hline Income & -- & -- & $0.494^{* *}$ & 7.33 & -- & -- & -- & -- & $0.786^{* *}$ & 5.85 & -- & -- \\
\hline Livestock_ 2010 & $0.465^{* *}$ & 8.50 & -- & -- & -- & -- & $0.527^{* *}$ & 6.46 & -- & -- & -- & -- \\
\hline Livestock_2012 & -- & -- & -- & -- & $0.568^{* *}$ & 12.4 & -- & -- & -- & -- & $0.851^{* *}$ & 10.2 \\
\hline LS_2012/Grassland & -- & -- & -- & -- & $-0.186^{* *}$ & -3.83 & -- & -- & -- & -- & $-0.373^{* *}$ & -2.65 \\
\hline Distance & -- & -- & $0.160^{* *}$ & 2.31 & -- & -- & -- & -- & $0.179^{* *}$ & 1.94 & -- & -- \\
\hline Race & -- & -- & $0.592^{* *}$ & 3.97 & -0.072 & -0.62 & -- & -- & $0.526^{* *}$ & 3.15 & $-0.325^{* *}$ & -1.94 \\
\hline Education & -- & -- & -- & -- & $0.046^{* *}$ & 3.04 & -- & -- & -- & -- & $0.046^{* *}$ & 2.88 \\
\hline Age & -- & -- & -- & -- & -0.065 & -0.27 & -- & -- & -- & -- & -0.210 & -0.81 \\
\hline
\end{tabular}




\begin{tabular}{|c|c|c|c|c|c|c|c|c|c|c|c|c|}
\hline D2 (Ulanqab) & $-2.337^{* *}$ & -2.99 & 0.500 & 0.55 & 0.096 & 0.70 & $-2.17^{* *}$ & -2.12 & 0.904 & 0.62 & 0.198 & 1.29 \\
\hline D3 (Ordos) & -1.009 & -1.32 & $1.530^{*}$ & 1.74 & 0.190 & 1.62 & $-0.875^{* *}$ & -1.99 & 1.889 & 1.64 & 0.239 & 1.26 \\
\hline D4 (Hulunbuir) & -0.822 & -0.83 & $2.341^{* *}$ & 2.07 & $-0.612^{* *}$ & -3.76 & -0.580 & -1.29 & $2.661^{* *}$ & 2.29 & $-0.826^{* *}$ & -6.29 \\
\hline Intercept & $2.01^{* *}$ & 3.62 & $-2.88^{* *}$ & -3.38 & $6.37^{* *}$ & 6.53 & $2.203^{* *}$ & 4.56 & $-5.87^{* *}$ & -3.93 & $5.72^{* *}$ & 5.79 \\
\hline $\mathrm{R}^{2}$ & \multicolumn{2}{|c|}{0.519} & \multicolumn{2}{|c|}{0.399} & \multicolumn{2}{|c|}{0.418} & \multicolumn{2}{|c|}{0.500} & \multicolumn{2}{|c|}{0.349} & \multicolumn{2}{|c|}{0.327} \\
\hline S.E. of regression & \multicolumn{2}{|c|}{0.844} & \multicolumn{2}{|c|}{0.983} & \multicolumn{2}{|c|}{0.734} & \multicolumn{2}{|c|}{0.860} & \multicolumn{2}{|c|}{1.024} & \multicolumn{2}{|c|}{0.790} \\
\hline Instrument Rank & \multicolumn{2}{|c|}{--} & \multicolumn{2}{|c|}{-- } & \multicolumn{2}{|c|}{--} & \multicolumn{2}{|c|}{19} & \multicolumn{2}{|c|}{29} & \multicolumn{2}{|c|}{16} \\
\hline$J$-statistic & \multicolumn{2}{|c|}{--} & \multicolumn{2}{|c|}{--} & \multicolumn{2}{|c|}{--} & \multicolumn{2}{|c|}{9.43} & \multicolumn{2}{|c|}{11.4} & \multicolumn{2}{|c|}{4.53} \\
\hline Prob (J-statistic) & \multicolumn{2}{|c|}{-- } & \multicolumn{2}{|c|}{-- } & \multicolumn{2}{|c|}{-- } & \multicolumn{2}{|c|}{0.308} & \multicolumn{2}{|c|}{0.121} & \multicolumn{2}{|c|}{0.716} \\
\hline
\end{tabular}

Note: ${ }^{* *}$ and ${ }^{*}$ denotes significance at the $5 \%$ and $10 \%$ levels, respectively, based on a two-tail $t$-test. 
Table 4

Parameter values used to simulate the model

\begin{tabular}{lcccc}
\hline & \multicolumn{3}{c}{ Prefecture } \\
\cline { 2 - 5 } Parameter & Xilingol & Ulanqab & Ordos & Hulunbuir \\
\hline$\alpha_{G L}$ & 0.478 & 0.478 & 0.478 & 0.478 \\
$\alpha_{S}$ & -0.288 & 0.292 & 0.006 & -0.011 \\
$\beta_{Y}$ & 0.786 & 0.786 & 0.786 & 0.786 \\
$\beta_{S}$ & 0.355 & 0.355 & 0.355 & 0.355 \\
$\gamma_{Q}$ & 0.851 & 0.851 & 0.851 & 0.851 \\
$\gamma_{I}$ & -0.373 & -0.373 & -0.373 & -0.373 \\
$\gamma_{E}$ & 0.046 & 0.046 & 0.046 & 0.046 \\
\hline
\end{tabular}


Table 5.

Reduced-form elasticities for subsidy $\left(S^{*}\right)$ and education $(E D)^{\text {a }}$

\begin{tabular}{|c|c|c|c|c|c|c|c|c|}
\hline \multirow{2}{*}{$\begin{array}{l}\text { Endogenous } \\
\text { Variable }\end{array}$} & \multicolumn{2}{|c|}{ Xilingol } & \multicolumn{2}{|c|}{ Ulanqab } & \multicolumn{2}{|c|}{ Ordos } & \multicolumn{2}{|c|}{ Hulunbuir } \\
\hline & $S^{*}$ & $E D$ & $S^{*}$ & $E D$ & $S^{*}$ & $E D$ & $S^{*}$ & $E D$ \\
\hline$Q^{*}$ & -0.064 & 0.033 & 0.713 & 0.033 & 0.330 & 0.033 & 0.307 & 0.033 \\
\hline$G L^{*}$ & 0.468 & 0.069 & 0.881 & 0.069 & 0.678 & 0.069 & 0.665 & 0.069 \\
\hline$I^{*}$ & -0.532 & -0.036 & -0.168 & -0.036 & -0.348 & -0.036 & -0.358 & -0.036 \\
\hline$Y^{*}$ & 0.144 & 0.087 & 0.670 & 0.087 & 0.410 & 0.087 & 0.395 & 0.087 \\
\hline
\end{tabular}

a Computed using parameter values in table 4 and matrix equation in Appendix B. Q $Q^{*}, G L^{*}, I^{*}$ and $Y^{*}$ refer to livestock, grassland, grazing intensity, and income, respectively. 
Table 6.

Sensitivity of reduced-form elasticities with respect to subsidy to the production elasticity $\alpha_{G L}$

\begin{tabular}{|c|c|c|c|c|c|c|c|c|}
\hline \multirow[b]{2}{*}{ Prefecture } & \multicolumn{2}{|c|}{$Q^{*} / S^{*}$} & \multicolumn{2}{|c|}{$G L^{*} / S^{*}$} & \multicolumn{2}{|c|}{$I^{*} / S^{*}$} & \multicolumn{2}{|c|}{$Y^{*} / S^{*}$} \\
\hline & $\alpha_{G L}=0.036$ & $\alpha_{G L}=0.920$ & $\alpha_{G L}=0.036$ & $\alpha_{G L}=0.920$ & $\alpha_{G L}=0.036$ & $\alpha_{G L}=0.920$ & $\alpha_{G L}=0.036$ & $\alpha_{G L}=0.920$ \\
\hline Xilingol & -0.275 & 0.340 & 0.356 & 0.683 & -0.631 & -0.343 & 0.001 & 0.418 \\
\hline Ulanqab & 0.316 & 1.475 & 0.670 & 1.286 & -0.354 & 0.189 & 0.401 & 1.185 \\
\hline Ordos & 0.021 & 0.910 & 0.514 & 0.986 & -0.492 & -0.076 & 0.202 & 0.803 \\
\hline Hulunbuir & 0.007 & 0.882 & 0.506 & 0.971 & -0.499 & -0.089 & 0.192 & 0.784 \\
\hline
\end{tabular}

Note: 0.036 and 0.920 are the limits of the $95 \%$ confidence interval for the long-run value of $\alpha_{G L}$ based on the GMM estimates in table 3 . 
Table 7.

Estimated cost to reduce grazing intensity to 1.3 sheep-equivalent units per hectare in Inner Mongolia

\begin{tabular}{|c|c|c|c|c|c|c|c|c|}
\hline Prefecture & $\begin{array}{c}\text { Initial } \\
\text { Subsidy } \\
(\$ / \text { ha })\end{array}$ & $\begin{array}{c}\text { Initial } \\
\text { Grazing } \\
\text { Intensity }^{\mathrm{a}} \\
\left(\mathrm{I}^{0}\right)\end{array}$ & $\begin{array}{l}\text { Desired } \\
\text { Grazing } \\
\text { Intensity } \\
\quad\left(I^{\prime}\right)\end{array}$ & $\begin{array}{c}\text { Percentage } \\
\text { Difference } \\
\text { between } \\
\mathrm{I}^{\prime} \text { and } \mathrm{I}^{0}\end{array}$ & $\begin{array}{l}\text { Subsidy } \\
\text { Elasticity } \\
\left(\mathrm{I}^{*} / S^{*}\right)^{\mathrm{b}}\end{array}$ & $\begin{array}{l}\text { Percentage } \\
\text { Increase in } \\
\text { Subsidy } \\
\text { Required to } \\
\text { Achieve I' c }\end{array}$ & $\begin{array}{l}\text { Subsidy } \\
\text { Required to } \\
\text { Achieve } \\
\text { I'd }^{\prime} \\
(\$ / \mathrm{ha}) \\
\end{array}$ & $\begin{array}{c}\text { Added } \\
\text { Cost to } \\
\text { Achieve } \\
\text { I' e } \\
(\$ / \mathrm{ha})\end{array}$ \\
\hline Column: & (a) & (b) & (c) & (d) & (e ) & (f) & (g) & (h) \\
\hline Xilingol & 24.5 & 1.77 & 1.30 & -26.6 & -0.532 & 50 & 36.7 & 12.2 \\
\hline Ulanqab & 13.1 & 3.88 & 1.30 & -66.5 & -0.168 & 396 & 65.0 & 51.9 \\
\hline Ordos & 9.7 & 1.98 & 1.30 & -34.3 & -0.348 & 99 & 19.3 & 9.6 \\
\hline Hulunbuir & 8.5 & 1.71 & 1.30 & -24.0 & -0.358 & 67 & 14.2 & 5.7 \\
\hline
\end{tabular}

a Sheep-equivalent animal units per hectare taken from table 2.

${ }^{b}$ Reduced-form elasticity of grazing intensity with respect to subsidy taken from table 5 .

c Column d divided by column e.

d Column a multiplied by $(1+$ column $\mathrm{f} / 100)$.

e Column g minus column a. 


\section{Appendix A. Derivation of the model's reduced form}

To begin, substitute equation (5) into (6) and rewrite the structural model as follows

$$
\begin{aligned}
& G L^{*}=\beta_{Y} Y^{*}+\beta_{S} \bar{S}^{*} \\
& Q^{*}=\alpha_{G L} \beta_{Y} Y^{*}+\left(\alpha_{G L} \beta_{S}+\alpha_{S}\right) \bar{S}^{*} \\
& Y^{*}=\gamma_{Q} Q^{*}+\gamma_{I} I^{*} \\
& I^{*}=-\beta_{Y}\left(1-\alpha_{G L}\right) Y^{*}+\left(\alpha_{S}-\beta_{S}\left(1-\alpha_{G L}\right)\right) \bar{S}^{*}
\end{aligned}
$$

Reduced-form equation for grazing intensity

First, substitute equation (A2) into (A3) to yield

$$
Y^{*}=\frac{\gamma_{I}}{1-\gamma_{Q} \alpha_{G L} \beta_{Y}} I^{*}+\frac{\gamma_{Q}\left(\alpha_{G L} \beta_{S}+\alpha_{S}\right)}{1-\gamma_{Q} \alpha_{G L} \beta_{Y}} \bar{S}^{*} .
$$

This equation may be rewritten more simply as

$$
Y^{*}=\Omega_{I} I^{*}+\Omega_{Q} \bar{S}^{*}
$$

where $\Omega_{I}=\frac{\gamma_{I}}{1-\alpha_{G L} \beta_{Y} \gamma_{Q}}$ is the feedback effect of grazing intensity on income, and $\Omega_{Q}=$ $\frac{\gamma_{Q}\left(\alpha_{G L} \beta_{S}+\alpha_{S}\right)}{1-\alpha_{G L} \beta_{Y} \gamma_{Q}}$ is the feedback effect of farm size on income. The signs of the feedback effects are uncertain.

Next, substitute equation (A5) into (A4) to yield

$$
I^{*}=\frac{\alpha_{S}-\left(\beta_{S}+\Omega_{Q} \beta_{Y}\right)\left(1-\alpha_{G L}\right)}{1+\Omega_{I} \beta_{Y}\left(1-\alpha_{G L}\right)} \bar{S}^{*} .
$$

Reduced-form equation for income

Substitute equation (A6) into (A5) to yield

$$
Y^{*}=\frac{\Omega_{Q}+\Omega_{I}\left(\alpha_{S}-\beta_{S}\left(1-\alpha_{G L}\right)\right)}{1+\Omega_{I} \beta_{Y}\left(1-\alpha_{G L}\right)} \bar{S}^{*} .
$$


Reduced-form equation for livestock units

Substitute equation (A7) into (A2) to yield

$$
Q^{*}=\frac{\alpha_{G L}\left(\beta_{S}+\Omega_{Q} \beta_{Y}\right)+\alpha_{S}\left(1+\Omega_{I} \beta_{Y}\right)}{1+\Omega_{I} \beta_{Y}\left(1-\alpha_{G L}\right)} \bar{S}^{*} .
$$

Reduced-form equation for grassland

Substitute equation (A7) into (A1) to yield

$$
G L^{*}=\frac{\beta_{Y}\left(\Omega_{Q}+\Omega_{I} \alpha_{S}\right)+\beta_{S}}{1+\Omega_{I} \beta_{Y}\left(1-\alpha_{G L}\right)} \bar{S}^{*} .
$$

Equations (A6) - (A9) constitute the model's reduced form.

\section{Appendix B. Simulation model}

Suppressing all exogenous variables in the econometric model except subsidy and education, the model may be written in parametric form as follows

$$
\begin{aligned}
& Q^{*}-\alpha_{G L} G L^{*}=\alpha_{S} \bar{S}^{*} \\
& G L^{*}-\beta_{Y} Y^{*}=\beta_{S} \bar{S}^{*} \\
& Y^{*}-\gamma_{Q} Q^{*}-\gamma_{I} I^{*}=\gamma_{E} \overline{E D} \\
& I^{*}-Q^{*}+G L^{*}=0
\end{aligned}
$$

where the education variable $\overline{E D}$ is expressed in level rather than proportionate change form to be consistent with the econometric estimate of its parameter $\gamma_{E}$.

Letting $\mathbf{Y}$ be a $4 \times 1$ vector of endogenous variables, and $\mathbf{X}$ be a $2 \times 1$ vector of exogenous variables, the model may be written more compactly as follows

$$
\mathbf{a Y}=\mathbf{b X}
$$


where $\mathbf{a}$ is a $4 \times 4$ matrix of endogenous-variable coefficients, and $\mathbf{b}$ is a $4 \times 2$ matrix of exogenous-variable coefficients.

Pre-multiplying equation (B5) by $\mathbf{a}^{-\mathbf{1}}$ yields

$$
\mathbf{Y}=\mathbf{E} \mathbf{X}
$$

where $\mathbf{E}=\mathbf{a}^{-\mathbf{1}} \mathbf{b}$ is a $4 \times 2$ matrix of reduced-form elasticities. Equation (B6) forms the basis for the elasticities presented in table 5 . 


\section{References:}

Agarwal, M., Shukla, A., Pal, V.N. 1993. Grazing of forested grassland and its conservation. Ecol. Model. 69, 57-62.

Banks, T. 2001. Property rights and the environment in pastoral China: Evidence from the field. Dev. Change 32(4), 717-740.

Brown, C., Waldron, S., Zhao Y. 2011. Policy settings to combat grassland degradation and promote sustainable development in western China. In Kemp, D.R., Michalk, D.L. (Eds), Development of Sustainable Livestock Systems on Grasslands in North-western China. ACIAR Proceedings No. 134, 105-114.

Brown, J.H., Mcdonald, W. 1995. Livestock grazing and conservation on southwestern rangelands. Conserv. Biol. 9, 1644-1647.

Cole, L.J., McCracken, D.I., Baker, L., Parish, D. 2007. Grassland conservation headlands: their impact on invertebrate assemblages in intensively managed grassland. Agric. Ecosyst. Environ. 122, 252-258.

Cuddington, J. T., Dagher, L. 2015. Estimating short and long-run demand elasticities: a primer with energy-sector applications. Energy J. 36,185-209.

Curtin, C.G. 2002. Livestock grazing, rest, and restoration in arid landscapes. Conserv. Biol. 16, 840-842.

DAIM (Department of Agriculture and Husbandry Animal in Inner Mongolia Autonomous Region). 2011. Implementation plan of "grassland ecological protection subsidies reward mechanism "in Inner Mongolia Autonomous Region. 2011-12-20.] http://zfs.mep.gov.cn/hjjj/gjfbdjjzc/stbczc1/201412/t20141224_293427.htm

David R. K., Han G., Hou X., David L.M., Hou F., Wu J., Zhang Y. 2013. Innovative grassland management systems for environmental and livelihood benefits. Proc. Natl. Acad. Sci., 8369-8374, doi: 10.1073/pnas.1208063110.

Feng, Z., Yang, Y., Zhang, Y., Zhang, P., Li, Y. 2005. Grain-for-green policy and its impacts on grain supply in West China. Land Use Policy 22(4): 301-312.

Fleischner, T.L. 1996. Conservation Biology Fundamentals. Conserv. Biol. 10(2), 692-693.

Gibson C.W.D., Brown V.K., Losito L., McGavin G.C. 1992. The response of invertebrate assemblies to grazing. Ecography, 15, 166-176.

Grant, S.A., Torvell, L, Common, T.G., Sim, E.M., Small, J.L. 1996. Controlled grazing studies on Molinia grassland: Effects of different seasonal patterns and levels of defoliation on Molinia growth and responses of swards to controlled grazing by cattle. J. Appl. Ecol. 33, 1267-1280.

Hao, L., Sun, G., Liu, Y., Gao, Z., He, J., Shi, T., Wu, B. 2014 Effects of Precipitation on Grassland Ecosystem Restoration under Grazing Exclusion in Inner Mongolia, China. Landscape Ecology 29(10), 1657-1673.

Han, J.G., Zhang, Y.J., Wang, C.J., Bai, W.M., Wang, Y.R., Han, G.D., Li, L. H. 2008. 
Rangeland degradation and restoration management in China. The Rangeland J. 30, 233-239.

Harris, R. B. 2010. Rangeland degradation on the Qinhai-Tibetan plateau: A review of the evidence of its magnitude and causes. J. Arid Environ. 74, 1-12.

Ho, P., Azadi, H. 2010. Rangeland degradation in North China: Perceptions of pastoralists. Environ. Res. 110, 302-307.

Hu, Z., Kong, D., Wei, T., Jin, L. 2015. Grassland Eco-compensation: Equivalent Relationship between Livestock Reduction and Compensation. J. of Natural resources 30 (11): 1846-1859. (in Chinese)

Hua, L., Squires, V.R. 2014. Managing China's pastoral lands: Current problems and future prospects. Land Use Policy 43, 129-147.

Hulme, P.D., Pakeman, R.J., Torvell, L., Fisher, J.M., Gordon, I.J. 1999. The effects of controlled sheep grazing on the dynamics of upland Agrostis-Festuca grassland. J. Appl. Ecol. 36, 886-900.

Jiang, H. 2006. Decentralization, ecological construction, and the environment in postreform China: Case study from Uxin banner, Inner Mongolia. World Dev. 4(11), 1907-1921.

John, R., Chen, J. Lu, N., Wilske, B. 2009. Land cover/land use change in semi-arid Inner Mongolia: 1992-2004. Environ. Res. Lett. 4, 45010-9, doi:10.1088/17489326/4/4/045010.

Johnston, A., Dormaar, J.F., Smoliak, S. 1971. Long-term grazing effects on fescue grassland soils. J. Range Manage. 24(3), 185-188.

Katoh, K., Takeuchi, K., Jiang, D., Nan, Y., Kou, Z. 1998. Vegetation restoration by seasonal exclosure in the Kerqin Sandy Land, Inner Mongolia. Plant Ecol. 139, 133144.

Kemp, D.R., Michalk, D.L. (Eds), 2011. Sustainable development of livestock systems on grasslands in North-Western China. ACIAR Proceedings 134. pp 189.

Kemp, D., Brown, C. Han, G., Michalk, D., Nan, Z., Wu, J., Zhu, X. 2012. Chinese grasslands: problems, dilemmas and finding solutions. In: Kemp, D.R., and Michalk, D.L. (Eds), Sustainable Development of Livestock Systems on Grasslands in North-Western China. ACIAR Proceedings 134, pp. 189.

Kolås, A. 2014. Degradation discourse and green governmentality in the Xilinguole grasslands of Inner Mongolia. Dev. Change 45(2), 308-328.

Leriche, H., LeRoux, X., Gignoux, J., Tuzet, A., Fritz, H., Abbadie, L., , Loreau, M. 2001. Which functional processes control the short-term effect of grazing on net primary production in grasslands? Oecologia 129, 114-124.

Li, Y., Ji, J. 2004. Assessment of the productivity and livestock carrying capacity of Inner Mongolia grassland by regional scale modeling (in Chinese). J. Nat. Resour. 19(5), 610-616. 
Li, Y., Y. Wang, R. Schwarze. 2014. Pathways in sustainable grassland development in China: Findings of three case studies. No 2/2014. UFZ Discussion Papers.

Liu, U., Wang, D. L., Han, S. J., Wang, X. 2004. Effect of grazing intensity on the regrowth capability of Leymus chinensis grassland. Acta Prataculturae Sinica 6, 39-44.

Marriott, C.A., Hood K., Fisher, J.M., Pakeman, R.J. 2009. Long-term impacts of extensive grazing and abandonment on the species composition, richness, diversity and productivity of agricultural grassland. Agric. Ecosyst. Environ. 134, 190-200.

Meyer, N. 2006. Desertification and restoration of grasslands in Inner Mongolia. J. Forestry 104, 328-331.

Nerlove, M. 1956. Estimates of the elasticities of supply of selected agricultural commodities. Am. J. Agr. Econ. 38 (2), 496-509.

Owen, M. 1977. The role of wildfowl refuges on agricultural land in lessening the conflict between farmers and geese in Britain. Biol. Cons. 11, 209-222.

Pakeman, R.J., Hulme, P.D., Torvell, L., Fisher, J.M. 2003. Rehabilitation of degraded dry heather [Calluna vulgaris (L.) Hull] moorland by controlled sheep grazing. Biol. Cons. 114(3), 389-400.

Purvis, G., Curry, J.P. 1981. The influence of sward management on foliage arthropod communities in a ley grassland. J. Appl. Ecol. 18, 711-725.

Rasran, L., Vogt, K., Jensen, K. 2007. Effects of topsoil removal, seed transfer with plant material and moderate grazing on restoration of riparian fen grasslands. Appl. Veg. Sci. 10, 451-460.

Schönbach, P., Wan, H., Gierus, M., Bai, Y., Müller, K., Lin, L., Susenbeth, A., Taube, F., 2011. Grassland responses to grazing: effects of grazing intensity and management system in an Inner Mongolian steppe ecosystem. Plant Soil 340, 103-115, doi:10.1007/s11104-010-0366-6.

Smart, M., Coutts, K. 2004. Footdrain management to enhance habitat for breeding waders on lowland wet grassland at Buckenham and Cantley Marshes, Mid-Yare RSPB Reserve, Norfolk, England. Conservation Evidence 1, 16-19.

Smith, R.S., Pullan, S., Shiel, R.S. 1996. Seed shed in the making of hay from mesotrophic grassland in a field in northern England: Effects of hay cut date, grazing and fertilizer in a split-split-plot experiment. J. Appl. Ecol. 33, 833-841.

State Council of China. 2002. The act of Conversion of degraded farm land into forest (No.367 Act of State Council, China). http://www.lawinfochina.com/display.aspx?lib=law\&id=2645\&CGid=

State Council of China. 2011. Several opinions on promoting the development of pastoral areas nice and fast. http://www.gov.cn/zwgk/201108/09/content_1922237.htm

Tallowin, J., Rook, A.J., Rutter, S.M. 2005. Impact of grazing management on biodiversity of grasslands. Anim. Sci. 81, 193-198. 
Wakeham-Dawson, A., Szoszkiewicz, K., Stern, K., Aebischer, N.J. 1998. Breeding skylarks Alauda arvensis on environmentally sensitive area arable reversion grass in southern England: survey-based and experimental determination of density. J. Appl. Ecol. 35, 635-648.

Waldron, S., Brown, C., Zhao Y. 2011. Policy settings to combat grassland degradation and promote sustainable development in western China. In Kemp, D.R., Michalk, D.L. (Eds), Development of Sustainable Livestock Systems on Grasslands in North-western China. ACIAR Proceedings No. 134, 98-104.

Wang, S. P. 2000. Relationships between body gain and stocking rates of grazing sheep on typical grassland in Inner Mongolia. Chinese J. of App. Ecol. 10, 437-441.

Wang, F., Pan, X., Wang, D., Shen, C., Lu, Q. 2013. Combating desertification in China: Past, present and future. Land Use Policy, 31, 311-313.

Yang, H., Jiang, L., Li, L., Li, A., Wu, M., Wan, S. 2012. Diversity-dependent stability under mowing and nutrient addition: evidence from a 7-year grassland experiment. Ecol. Lett. 15(6), 619-626.

Yeh, E.T. 2009. Greening western China: A critical view. Geoforum, 40, 884-894.

Yu, M., Ellis, J. E., and Epstein, H. E. 2004. Regional analysis of climate, primary production, and livestock density in Inner Mongolia. J. Environ. Quality 33, 16751681.

Zhao, H., Zhao, X., Zhou, R., Zhang, T., Drake, S. 2005. Desertification processes due to heavy grazing in sandy rangeland, Inner Mongolia. J. Arid. Environ. 62, 309-319.

Zhen, L., Li, F., Yan, H.M., Liu, G.H., Liu, J.Y., Zhang, H.Y., Du, B.Z., Wu, R.Z., Sun, C.Z, and Wang, C. 2014. Herders' willingness to accept versus the public sector's willingness to pay for grassland restoration in the Xilingol league of Inner Mongolia, China. Environ. Res. Lett. 9, 045003 (15pp). 